\title{
ATRIBUTOS MORFOLÓGICOS DE TUBÉRCULOS EN GENOTIPOS DE SOlanum phureja Juz et Buk Y SU RELACIÓN CON LA INCIDENCIA DE LA SARNA POLVOSA
}

\section{MORPHOLOGICAL TUBER CHARACTERISTICS IN GENOTYPES OF Solanum phureja Juz et Buk AND ITS RELATIONSHIP WITH POWDERY SCAB INCIDENCE.}

Carlos Andrés Palacios Bejarano $0^{1,3} \bullet$ José Miguel Cotes Torres ${ }^{2}$

\section{RESUMEN}

El objetivo de este trabajo es determinar si existe relación entre las características morfológicas de genotipos de Solanum phureja de la colección de trabajo de la Universidad Nacional de Colombia y la respuesta al ataque de la sarna polvosa en tubérculos. Se evaluaron 93 genotipos y de cada uno se cosecharon diez tubérculos en el municipio de La Unión (Ant). Se determinó la densidad y el área de las lenticelas, el grosor de la peridermis, el color y forma de los tubérculos. Los datos obtenidos se confrontaron con la información de la incidencia de la sarna polvosa en tubérculos, bajo condiciones de campo. Se encontró que existe una amplia variabilidad genética en la colección evaluada para todas las características morfológicas de tubérculos. Los tubérculos de color negro presentaron mayor densidad y área de lenticelas y el menor grosor de peridermis, mientras que los genotipos rojizos presentaron menores densidades y área de lenticelas y valores intermedios para el grosor de la peridermis. Por otro lado los tubérculos alargados presentan mayor densidad de lenticelas y menor grosor de peridermis, mientras que los tubérculos ovalados presentan el comportamiento contrario. Igualmente se encontró que los tubérculos redondos presentaron bajos valores de densidad de lenticelas y grosor de la peridermis. No se encontró relación entre las características morfológicas evaluadas y la incidencia de la sarna polvosa en campo.

Palabras Claves: Grosor peridermis, densidad de lenticelas, área de lenticelas.

1 Estudiante Maestría en Ciencias Agrarias. Institución: Universidad Nacional de Colombia - Sede Medellín - Facultad de Ciencias Agrarias - Departamento de Ciencias Agronómicas - CII. 59A No 63-20 - Núcleo El Volador, Medellín - Colombia.

2 Profesor Asociado. Institución: Universidad Nacional Colombia - Sede Medellín - Facultad de Ciencias Agrarias - Departamento de Ciencias Agronómicas - Cll. 59A No. 63-20 - Núcleo El Volador, Medellín - Colombia

3 Autor para correspondencia: jmcotes@unal.edu.co 


\section{ABSTRACT}

This research was carried out to determine the correlation between the morphological characteristics of Solanum phureja genotypes from germplasm collection of the National University of Colombia and its response to the symptoms of powdery scab on tubers. 93 genotypes were evaluated, ten tubers for each genotype were harvested from La Union (Ant). Both, density and lenticels area, periderm thickness, color skin and shape of the tubers was determined. The data obtained were compared with the information about incidence of powdery scab on tubers under field conditions. We found a wide genetic variability in the collection evaluated for all the morphological characteristics of tubers. Black skin tubers showed the highest density and lenticels area and the lowest periderm thickness, while genotypes with red skin tuber had lowest densities and lenticels area, and intermediate values for the periderm thickness. Furthermore, long tubers had the highest density of lenticels and lowest periderm thickness, while ovoid tubers had the opposite tendency. Spherical tubers showed low density of lenticels and periderm thickness. No relationship between morphological characteristics and the incidence of powdery scab on field was found.

Keywords: Periderm thickness, lenticels density, lenticels area.

\section{INTRODUCCIÓN}

El parásito obligado Spongospora subterraneaf. sp. subterranea pertenece al orden Plasmodiophorales (Hoyos et al., 2009) y es agente causal de la sarna polvosa de la papa (Qu y Christ, 2007; Merz y Falloon, 2009), enfermedad que se encuentra distribuida en casi todas las regiones productoras de papa en el mundo, originando pérdidas en tubérculos para consumo, pérdidas en tubérculos semilla (Wale, 2000) afectando el funcionamiento de la raíz, y por ende la producción, pues en un estado avanzado de la enfermedad, las raíces se desintegran (Hoyos et al., 2009). Además de ser un importante patógeno primario de la papa, S. subterranea $f$. sp. subterranea es el vector del virus Mop top de la papa (PMTV) que causa una reducción del crecimiento en las plantas y genera la enfermedad conocida como "spraing" o pardeamiento interno de los tubérculos, la cual produce necrosis en forma de anillos o manchas de color marrón en los tubérculos (Burrows y Zitter, 2005; Prentice et al., 2007).
La enfermedad afecta raíces, estolones y tubérculos (Johnson, 2002). Los síntomas en tubérculos inician como pequeñas inflamaciones que, tras la elongación y división de las células del huésped, conducen a la ruptura de la peridermis. Las lesiones en tubérculos maduros tienen una apariencia similar a una sarna, y cada lesión se llena de bolas de esporas o quistosoros del patógeno. Por debajo de la lesión, la peridermis se oscurece y se deprime con el tiempo, dejando un hueco lleno de masas de quistosoros, estos liberan las zoosporas que infectan a los tubérculos semilla y permiten que el patógeno persista en el suelo (Falloon et al., 2005).

El mecanismo de infección ha sido estudiado en detalle en otros miembros de los plasmodiophorales como Plasmodiophora brassicae Woronin (Aist y Williams, 1971), Polymyxa betae keskin (Harrison et al., 1997) y en Spongospora subterranea f. sp. nasturtii (Claxton et al., 1996), todos estos autores describen mecanismos similares de penetración de las zoosporas en la célula del hospedero y el desarrollo de una 
estructura especializada denominada "stachel", la cual se une a la pared celular e inyecta rápidamente el contenido de las zoosporas al interior de las células; sin embargo, son pocos los estudios que se han hecho de S. subterranea f. sp. subterranea (Lahert y Kavanagh, 1985 Merz, 1997; Ward y Adams, 2010).

Las primeras etapas del cultivo parecen ser el momento crítico para la infección de S. subterranea (Diriwächter y Parbery, 1991; Montero-Astua y Rivera, 2005), lo cual ha sido demostrado, también, al no observarse aumento de la incidencia de la enfermedad cuando los tubérculos alcanzan la madurez (Van der Graaf et al., 2005). De acuerdo con Johnson (2002), el patógeno invade el tubérculo a través de las lenticelas, heridas y a veces, a través los ojos. Los síntomas del tubérculo son parecidos a los de la sarna común, sin embargo, las lesiones producidas por la sarna polvosa, son generalmente más pequeñas, circulares, de tamaño uniforme y rodeadas por una franja de cáscara de la papa, cuando maduran (Salas, 2005). Las zoospororas de S. subterranea f. sp. subterranea pueden afectar los tubérculos y las células de la epidermis de las raíces. La exudación de solutos a partir de lenticelas inmaduras puede actuar como atrayente para las zoosporas; sin embargo, la quimiotaxis en S. subterranea nunca ha sido demostrada (Harrison et al., 1997).

Se han identificado una serie de medidas para el control para la sarna polvosa, pero ningún método ha proporcionado un control efectivo. En consecuencia, Falloon et al., (2008) proponen una estrategia integrada de manejo como el método más adecuado para el control de la enfermedad, incorporando el mayor número posible de prácticas, para ofrecer así, un mayor control de la enfermedad. Dentro de las prácticas propuestas se destacan: la rotación de cultivos, el manejo de la humedad en campo y la fertilización, tratamientos químicos al suelo y a los tubérculos semilla, el uso de tubérculo semilla certificado (libre del patógeno) la asepsia en las labores propias del cultivo y la elección de cultivares resistentes.
Un componente clave en la estrategia de manejo integrado de las enfermedades es la resistencia del huésped (De Boer, 2000). Cultivares de papa resistentes a la sarna polvosa con características comercialmente aceptadas, son esenciales para el control eficaz y a largo plazo de la enfermedad. En la actualidad, los cultivares más explotados comercialmente, son susceptibles a la enfermedad. Bhattacharya et al., (1985) encontraron que de 513 genotipos de papa evaluados, sólo 13 fueron altamente resistentes y 397 fueron altamente susceptibles. Hasta ahora, no hay cultivares de papa que hayan sido clasificados como inmunes a la sarna polvosa.

Existen algunas pruebas de que la resistencia a la enfermedad puede ser expresada en las raíces y tubérculos (Schwärzel, 2002). Sin embargo, poco se sabe acerca de los mecanismos y la genética de la resistencia a la sarna polvosa.

Teniendo en cuenta lo anterior y considerando que es necesario avanzar en el conocimiento del patógeno y en el entendimiento de los mecanismos que le permiten al hospedante reaccionar y defenderse por sí solo, utilizando una serie de mecanismos naturales para esto; por medio de esta investigación se pretende determinar las características morfológicas de tubérculos en genotipos de Solanum phureja de la colección de trabajo de la Universidad Nacional de Colombia y su relación con la respuesta al ataque de la sarna polvosa (S. subterranea f. sp. subterranea).

\section{MATERIALES Y MÉTODOS}

\section{Siembra y muestreo de tubérculos}

Se sembraron 93 genotipos de la colección de trabajo de S. phureja de la Universidad Nacional de Colombia, en parcelas experimentales, en el municipio de La Unión (Ant). Dos semanas después de iniciarse la tuberización (tres semanas después de la floración), se tomó una muestra de entre siete y diez tubérculos de cada accesión. Posteriormente, 
los tubérculos fueron trasladados al Laboratorio de Sanidad Vegetal de la Universidad Nacional de Colombia, donde en principio se determinó el color y la forma para cada una de las accesiones. Se determinaron cuatro colores predominantes (tubérculos con cáscara amarilla, roja, negra y mixtas, estas últimas hacen referencia a la combinación de dos colores) y tres formas (tubérculos alargados, ovalados y redondos).

\section{Determinación de la densidad y área de lenticelas \\ La determinación de la densidad de lentice-} las se hizo aleatoriamente, tomando tres o cuatro tubérculos (dependiendo del tamaño) para cada genotipo y se contó el número de lenticelas por $\mathrm{cm}^{2}$, en diferentes regiones de la superficie de los tubérculos, hasta alcanzar diez mediciones, con la ayuda de un marco con plástico de $1 \mathrm{~cm}^{2}$. El área de lenticelas se determinó, midiendo diez lenticelas escogidas al azar para cada una de las muestras con la ayuda de un estereoscopio marca NIKON MZ100, provisto de una cámara microfotográfica. Todas las observaciones se hicieron con un aumento de $2 \mathrm{X}$.

Penetración de lenticelas por la safranina

La penetrabilidad de las lenticelas se evaluó utilizando el método de inmersión en una solución acuosa de Safranina al 1\% P/V, propuesto por Tyner et al., (1997). Se tomaron tres tubérculos de cada muestra y se sumergieron durante $60 \mathrm{~min}$ en dicha solución, luego se lavó el exceso del colorante y se pelaron las zonas alrededor de diez lenticelas a una profundidad aproximada de $1 \mathrm{~mm}$.

La penetración de las lenticelas se evidenció como una mancha roja en el tejido por debajo de la cáscara de los tubérculos y el porcentaje de lenticelas penetrado por la mancha se estimó visualmente.

\section{Grosor de la peridermis}

Para determinar el grosor de la peridermis se escogieron cinco tubérculos al azar de cada accesión y se realizaron cortes transversales de $50 \mu \mathrm{m}$ de espesor con la ayuda de un micrótomo manual., Posteriormente, los cortes se observaron con la ayuda de un estereoscopio marca NIKON SMZ100, con un aumento de $2 X$ y se procedió a realizar las mediciones.

\section{Análisis estadístico y confrontación} con datos de campo

Se realizaron análisis de varianza (ANOVA) para cada una de las variables evaluadas (densidad de lenticelas, área de lenticelas, penetrabilidad de la safranina a través de las lenticelas y grosor de la peridermis del tubérculo) y para determinar si existían diferencias entre los genotipos agrupados por el color de la cáscara y la forma del tubérculo semilla se utilizó la diferencia mínima significativa.

Los datos de incidencia de la enfermedad en tubérculos, provienen de 15 experimentos en campo, generados en un estudio paralelo del grupo de Mejoramiento y Producción de Especies Andinas y Tropicales, denominado "Evaluación fenotípica y genotípica de la Colección Colombiana de Solanum phureja por resistencia a Spongospora subterranea", usando la escala diagramática para la evaluación de severidad de la sarna polvosa en raíces (Cotes et al., 2012).

Con el fin de evaluar la asociación entre la incidencia de la enfermedad y los atributos morfológicos evaluados en raíces, se obtuvo el coeficiente de correlación lineal de Pearson.

Para el análisis de los datos se utilizó el ambiente de análisis de datos R (R Development Core Team, 2014).

\section{RESULTADOS Y DISCUSIÓN}

Al realizar el análisis de varianzas de las variables para los genotipos individuales, se encontraron 
diferencias significativas entre los genotipos ( $p<$ 0,0001 ) en todos los casos.

Se encontró que existe un amplio rango de variación de cada una de las variables en los genotipos evaluados, lo que manifiesta la alta diversidad genética contenida en la colección de trabajo de $S$. phureja. Así, para la densidad de lenticelas esta varía de 6,8 lenticelas $\cdot \mathrm{cm}^{-2}$ a 28,6 lenticelas $\cdot \mathrm{cm}^{-2}$, para los genotipos 120 y 30, respectivamente (Figura 1). En el

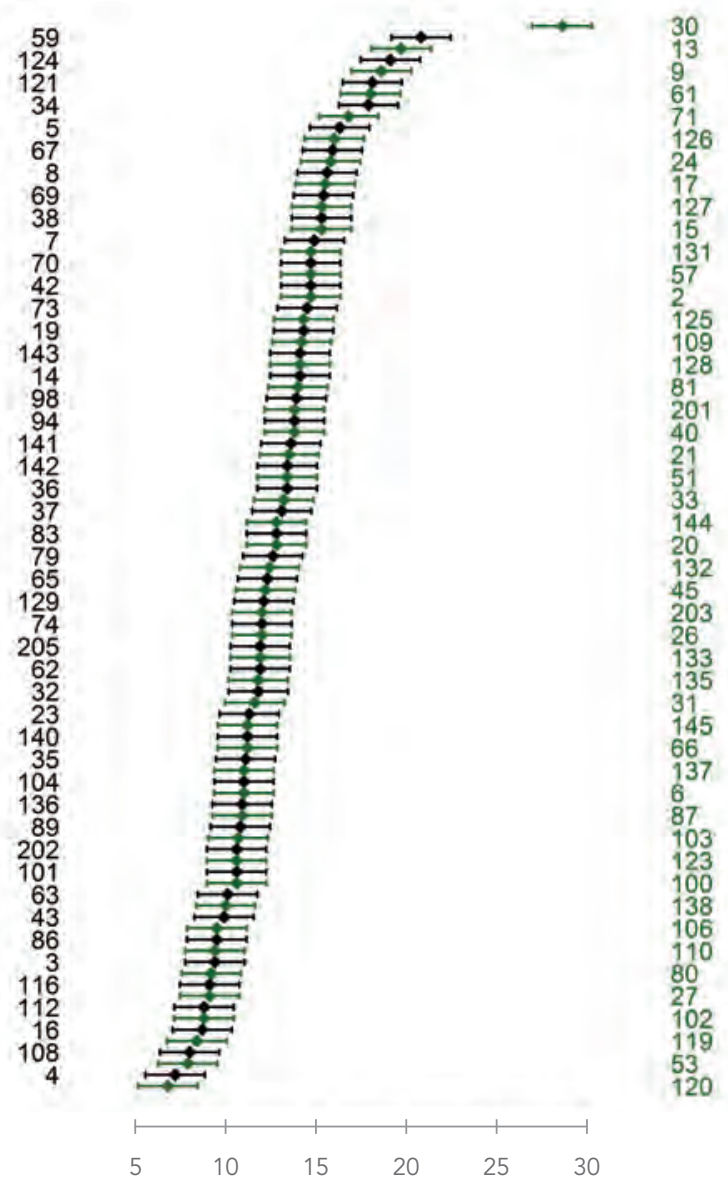

Figura 1. Valor estimado para la densidad de lenticelas (lenticelas $\cdot \mathrm{cm}^{-2}$ ) para cada uno de los genotipos evaluados. Las barras de error indican los límites del intervalo de confianza de $95 \%$. Las variedades comerciales son: Criolla Colombia (201), Criolla Galeras (202), Criolla Latina (204) y Criolla Paisa (205)

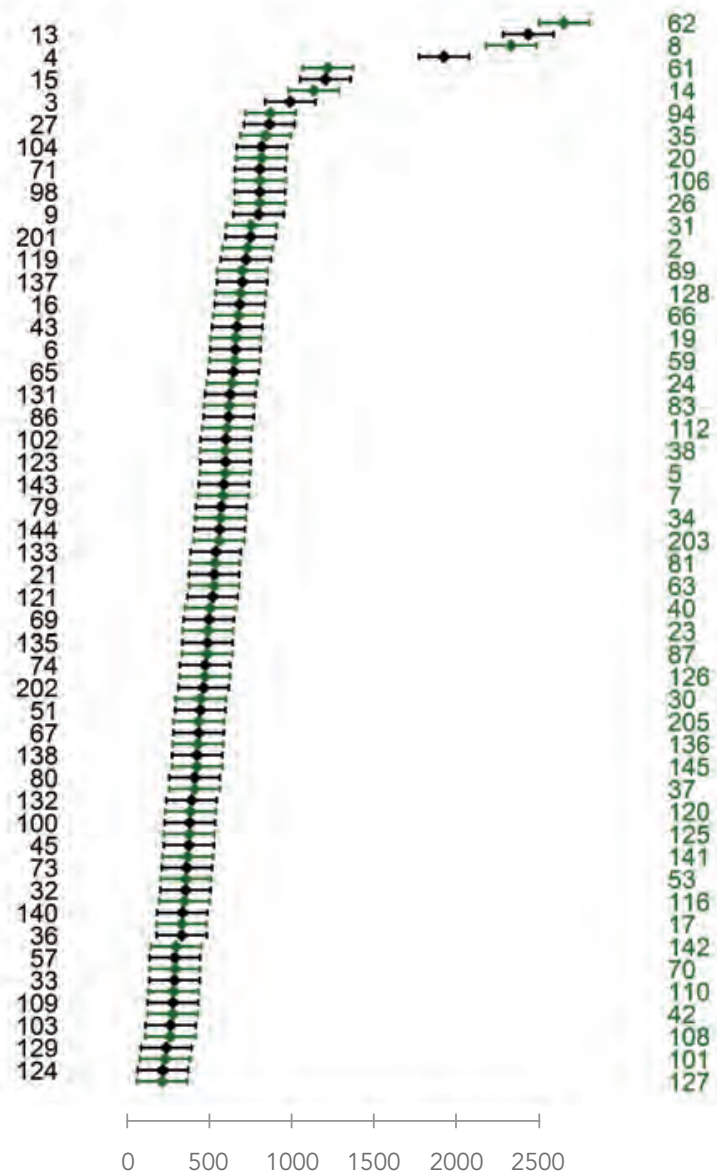

Figura 2. Valor estimado para el área de las lenticelas $\left(\mu \mathrm{m}^{2}\right)$ para cada uno de los genotipos evaluados. Las barras de error indican los límites del intervalo de confianza de $95 \%$. Las variedades comerciales son: Criolla Colombia (201), Criolla Galeras (202), Criolla Latina (204) y Criolla Paisa (205).

caso del área de las lenticelas esta varía entre 195,87 $\mu \mathrm{m}^{2}$ y 2648,07 $\mu \mathrm{m}^{2}$, para los genotipos 127 y 62, respectivamente (Figura 2). Finalmente para el grosor de la peridermis se encontró una variación que oscila entre $21,15 \mu \mathrm{m}$ y $45,00 \mu \mathrm{m}$, para los genotipos 4 y 26, respectivamente (Figura 3).

En cuanto a la asociación entre las formas y los colores de la cáscara del tubérculo, frente a las variables evaluadas, se encontró que hay diferencias significativas en todas las variables cuando estas son agrupadas por colores, mientras que en forma sólo 

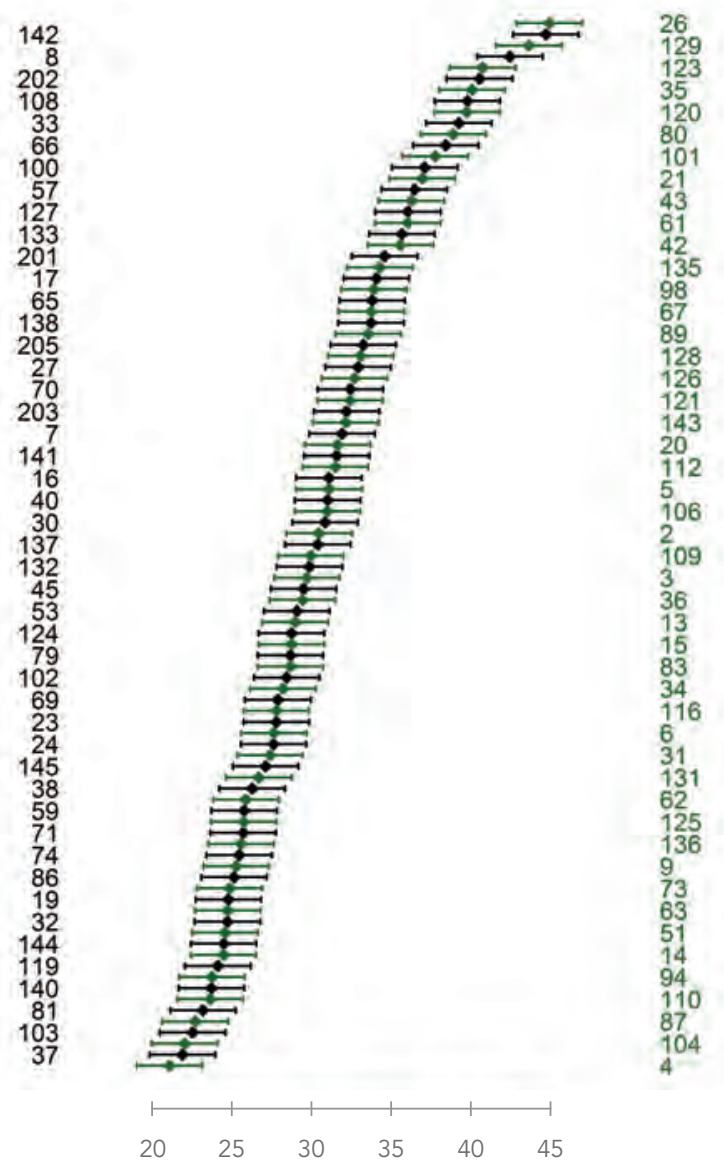

Figura 3. Valor estimado para el grosor de la peridermis ( $u \mathrm{~m})$ para cada uno de los genotipos evaluados. Las barras de error indican los límites del intervalo de confianza de 95\%. Las variedades comerciales son: Criolla Colombia (201), Criolla Galeras (202), Criolla Latina (204) y Criolla Paisa (205).

se presentaros diferencias significativas para las variables densidad de lenticelas y grosor de la peridermis.

Cuando se agrupa por colores de la cáscara del tubérculo se encuentran diferencias significativas entre las de color negro frente a los demás, siendo la de color negro las que presentan la mayor densidad (Figura 4). En el mismo sentido, cuando se observa el área de las lenticelas, se encuentran diferencias significativas entre el color negro y el rojo, siendo las negras las de mayor área (Figura 5). Finalmente, al evaluar el grosor de la peridermis se encuentran

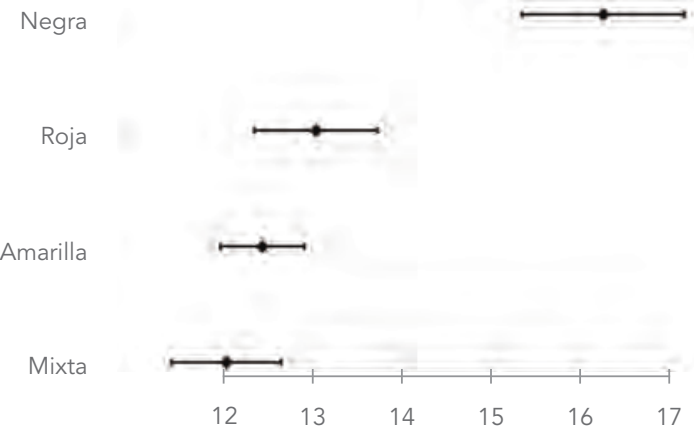

Figura 4. Valor estimado para la densidad de lenticelas (lenticelas $\cdot \mathrm{cm}^{-2}$ ) con respecto al color de la cáscara del tubérculo semilla. Las barras de error indican los límites del intervalo de confianza de 95\%.

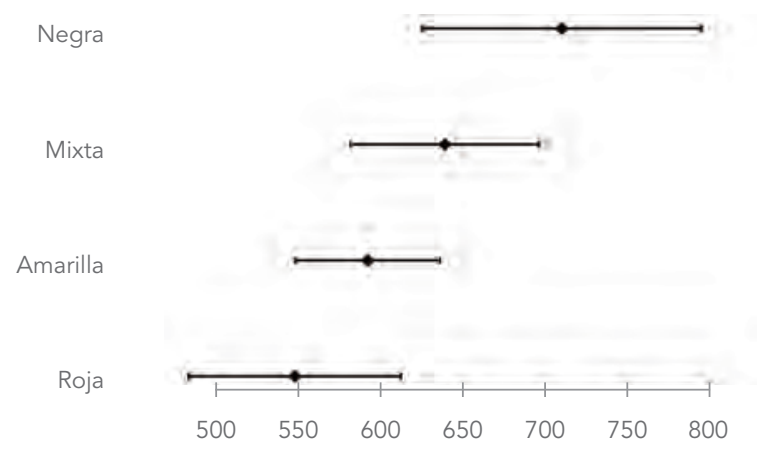

Figura 5. Valor estimado para el área de las lenticelas $\left(\mu \mathrm{m}^{2}\right)$ con respecto al color de la cáscara del tubérculo semilla. Las barras de error indican los límites del intervalo de confianza de 95\%.

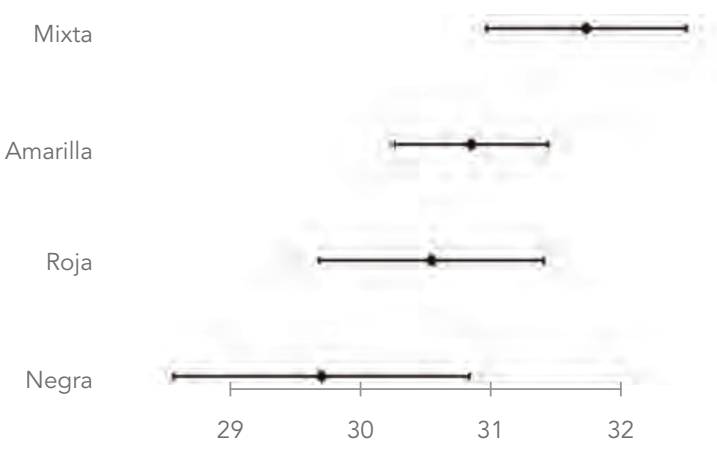

Figura 6. Valor estimado para el grosor de la peridermis ( $\mu \mathrm{m})$ con respecto al color de la cáscara del tubérculo semilla. Las barras de error indican los límites del intervalo de confianza de $95 \%$. 
diferencias significativas entre las de color mixto y las de color negro siendo las negras las de menor grosor (Figura 6). Así, se puede afirmar que los genotipos que producen tubérculos de color negro presentan mayor densidad y área de lenticelas y el menor grosor de peridermis, mientras que los genotipos rojizos presentan menores densidades y área de lenticelas y valores intermedios para el grosor de la peridermis.

En cuanto a la relación de las variables evaluadas con la forma de tubérculo se encontró que los genotipos que producen tubérculos de forma alargada presentan una mayor densidad de lenticelas frente a los genotipos que producen otras formas en los

$$
\text { Alargada }
$$

Redonda

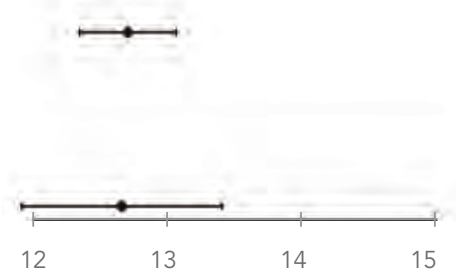

Figura 7. Valor estimado para la densidad de lenticelas (lenticelas $\cdot \mathrm{cm}^{-2}$ ) con respecto a la forma del tubérculo semilla. Las barras de error indican los límites del intervalo de confianza de 95\%.

Redonda

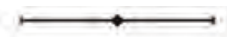

Ovalada

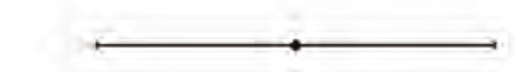

Alargada

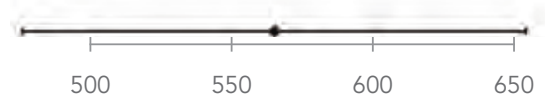

Figura 8. Valor estimado para área de las lenticelas $\left(\mu \mathrm{m}^{2}\right)$ con respecto a la forma del tubérculo semilla. Las barras de error indican los límites del intervalo de confianza de $95 \%$.

\section{Ovalada}

Redonda

Redonda

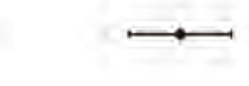

Alargada

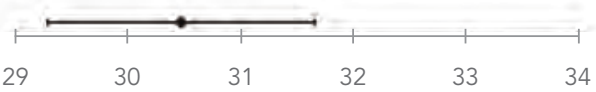

Figura 9. Valor estimado para el grosor de la peridermis $(\mu \mathrm{m})$ con respecto a la forma del tubérculo semilla. Las barras de error indican los límites del intervalo de confianza de 95\%.

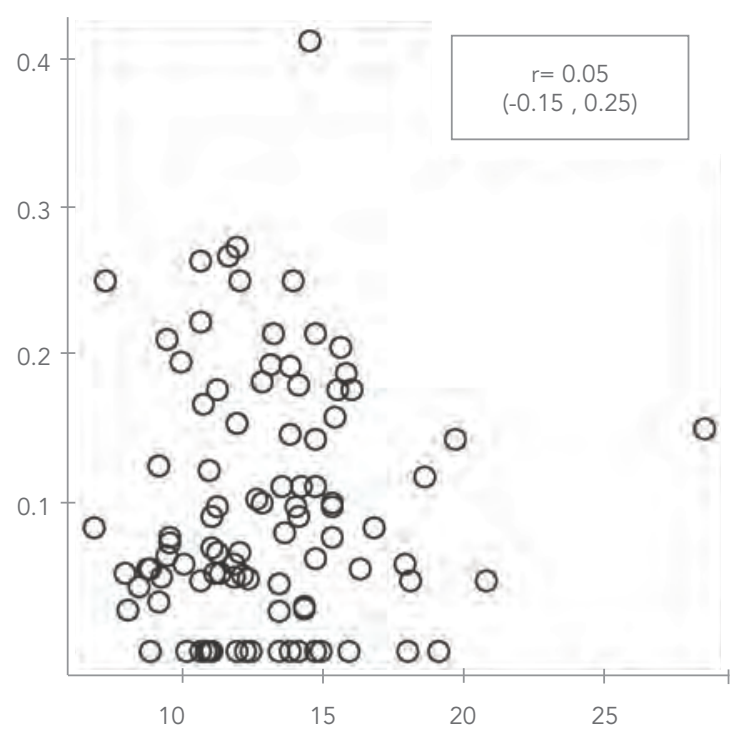

Figura 10. Relación entre el valor estimado para la densidad de lenticelas (lenticelas $\mathrm{cm}^{-2}$ ) (eje horizontal) y el valor de incidencia de sarna polvosa en tubérculos bajo condiciones de campo (eje vertical). En el recuadro se destaca la correlación linear de Pearson y su respectivo intervalo de confianza de $95 \%$. 


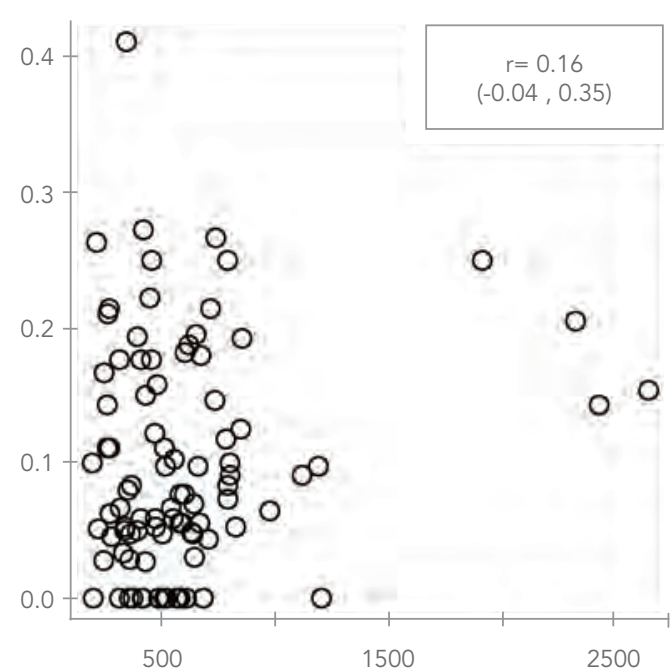

Figura 11. Relación entre el valor estimado para área de las lenticelas $\left(\mu \mathrm{m}^{2}\right)$ (eje horizontal) y el valor de incidencia de sarna polvosa en tubérculos bajo condiciones de campo (eje vertical). En el recuadro se destaca la correlación linear de Pearson y su respectivo intervalo de confianza de $95 \%$.

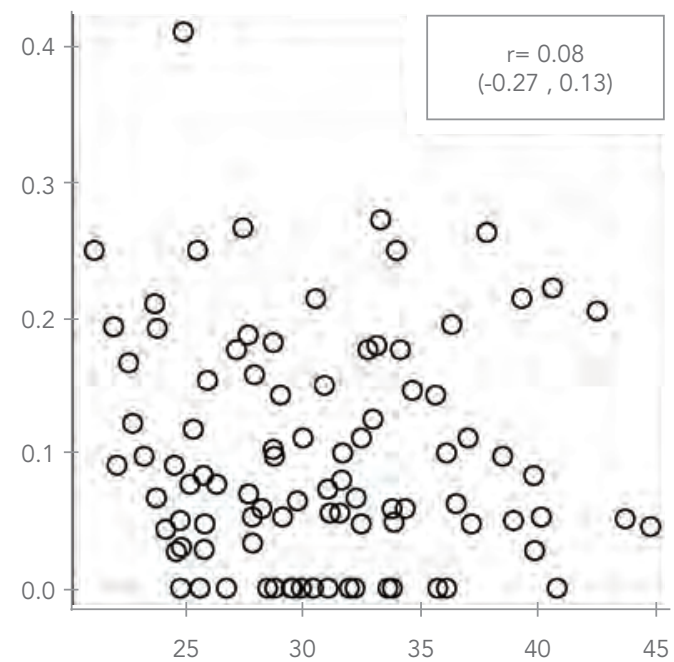

Figura 12. Relación entre el valor estimado para el grosor de la peridermis $(\mu \mathrm{m})$ (eje horizontal) y el valor de incidencia de sarna polvosa en tubérculos bajo condiciones de campo (eje vertical). En el recuadro se destaca la correlación linear de Pearson y su respectivo intervalo de confianza de $95 \%$. tubérculos (Figura 7). En lo referente al área de las lenticelas no se encontraron diferencias significativas (Figura 8) y para el grosor de la peridermis los genotipos con tubérculos ovalados presentaron valores más altos cuando se comparan con los clones que producen otras formas (Figura 9). Así se puede afirmar que los tubérculos alargados presentan mayor densidad de lenticelas y menor grosor de peridermis, mientras que los tubérculos ovalados presentan el comportamiento contrario. Igualmente se encuentra que los tubérculos redondos presentan bajos valores de densidad de lenticelas y grosor de la peridermis.

No se encontró correlación entre las características morfológicas evaluadas, es decir, densidad y área de lenticelas, y grosor de peridermis, con la incidencia de tubérculos en campo, (Figura 10, 11 y 12). Además, las gráficas entre las variables muestran un patrón aleatorio entre ellas por lo que no es posible encontrar, ni siquiera parcialmente, una asociación entre las mismas.

Estos resultados contrastan con lo reportado por Nitzan et al., (2008), Christ (1988) y Mohan et al., (1991), quienes demostraron que tubérculos con cáscara rojiza son menos susceptibles a la enfermedad, pero son propensos a la infección de las raíces. James y Crowe (1995), en trabajos realizados en EEUU, encontraron que variedades de papa con cáscara amarilla son más susceptibles a la sarna polvosa. Miller (2001), reporta que el cultivar Russet norkotah, cuya cáscara es de color roja, es resistente a la sarna polvosa, mientras que los cultivares Kennebec, Shenopy y Yukon gold, todas con cáscara amarilla, son susceptibles.

Iftikhar et al., (2007) realizaron ensayos en la India, donde evaluaron la susceptibilidad de seis cultivares en suelos naturalmente infectados con Spongospora subterranea, encontrando que solo el cultivar Desiree, cuya cascara es de color rojiza, tuvo una incidencia muy baja, en comparación con los otros materiales. 
Brierley et al., (2008) y Miller (2001), afirman que la susceptibilidad a la sarna polvosa disminuye, a medida que aumenta la suberizacíon de los tejidos del tubérculo, lo cual difiere de los resultados encontrados en este trabajo referente a la asociación entre el grosor de la peridermis y la incidencia de la enfermedad en tubérculos.

Por otro lado, en general, es deseable que las lenticelas tengan la menor área posible, si partimos del hecho de que estas estructuras son una de las principales entradas del patógeno, como lo afirman Diriwachter y Parbery (1991), Mohan et al., (1991) y Johnson (2002). Así se encontró que en la colección de trabajo de S. phureja hay una amplia dispersión de la variable siendo la relación entre el genotipo con menor y mayor área, de 13 veces, parámetro que podría ser utilizado para mejoramiento genético de la especie frente al ataque de diversos patógenos de suelo.

Es importante destacar que en los genotipos de $S$. phureja evaluados, la severidad de la enfermedad en tubérculos es muy baja (menor del 5\%), por lo que la falta de asociación de estas variables morfológicas de tubérculos y la incidencia de la enfermedad en tubérculos, no descarta que ellas correlacionen mejor con otras especies de papa del género Solanum que presenten una mayor severidad de la enfermedad en tubérculos.

\section{AGRADECIMIENTOS}

Esta investigación fue financiada a través del proyecto 20101008002- Evaluación fenotípica y genotípica de la colección colombiana de Solanum phureja por resistencia a Spongospora subterranea Fase II, financiado por la Vicedecanatura de Investigación y Extensión de la Facultad de Ciencias Agrarias. La presente investigación se desarrolló en los Laboratorios de Sanidad Vegetal y de Mejoramiento Genético de Plantas de la Facultad de Ciencias Agrarias de la Universidad Nacional de Colombia Sede Medellín. Los autores expresan sus agradecimientos a los integrantes de los grupos de investigación de Mejoramiento y producción de Especies Andinas y Tropicales (COL0039484) y al Grupo de Investigación en papa (COL0010065), que aportaron el recurso humano para desarrollar esta investigación.

\section{No se encontró relación entre las características morfológicas evaluadas y la incidencia de la sarna polvosa en campo.}




\section{BIBLIOGRAFÍA}

1. Aist J., Williams P. 1971. The cytology and kinetics of cabbage root hair penetration by Plasmodiophora brasiccae. Canadian Journal of Botany 49: 2023-2034.

2. Bhattacharya S., Ray S., Dwivedi R. 1985. Sources of resistance to powdery scab in potatoes. Indian Phytopathology 38: 174-175.

3. Brierley J., Less A. 2008. Powdery scab-Strains and conducive conditions. Research review. Agriculture \& Horticulture Development Board (AHDB). Potato Council Ltd., Oxford, UK, 43p.

4. Burrows M., Zitter T. 2005. Problemas de virus en papa. USDA-ARS and Department of Plant Pathology Cornell University, Ithaca, NY, 7p.

5. Christ B., Weidner R. 1988. Incidence and Severity of Powdery Scab on Potatoes in Pennsylvania. American Potato Journal 65: 583-588.

6. Claxton U., Potter J., Blakesley D., Clarkson. M. 1996. An ultrastructural study of the interaction between Spongospora subterranea f. sp. nasturtii and watercress roots. Mycological Research 100:1431-1439.

7. Cotes J.M., González E.P., Zuluaga C.M., Morales J.G., Marín M.A., Ñustez C.E. 2012. Informe final de proyecto de investigación "Evaluación fenotípica y genotípica de la colección de Solanum phureja por su resistencia a Spongospora subterranea f. sp. subterranea". Universidad Nacional de Colombia y Politécnico Colombiano Jaime Isaza Cadavid, Medellín, Colombia, 94p.
8. De Boer R, 2000. Summary of the session on recognizing the components of an integrated control approach to powdery scab and the potato mop top virus. p 101-104. En: Merz U., Lees A.K. (eds). The 1st European Powdery Scab Workshop, 2000. Aberdeen, UK. 102p.

9. Diriwachter G., Parbery D. 1991. Infection of potato by Spongospora subterranea. Mycological Research 95: 762- 764.

10. Falloon R. 2008. Control of powdery scab of potato; towards integrated disease management. American Journal of Potato Research 85: 253-260.

11. Falloon R., Genet R. Wallace, A. Braam, W. 2005. Resistance to Powdery Scab (Spongospora subterranea) in Potatoes. A Key Component of Integrated Disease Management. Acta Horticulturae 670: 57-62.

12. Harrison J., Searle R., Williams N. 1997. Powdery scab disease of potato. A review. Plant Pathology 46: 1-25.

13. Hoyos L., Villegas M., González E. 2009. Observaciones histológicas de estructuras celulares asociadas a Spongospora subterranea f. sp. subterranea en papa. Revista Facultad Nacional de Agronomía, Medellín 62: 5039-5045.

14. Iftikhar S., Rattu A., Asad S., Burney K. 2007. Susceptibility of potato cultivars to Spongospora subterranea under field conditions. $\mathrm{Pa}$ kistan Journal of Botany 39: 1329-1333. 
15. James R., Crowe F. 1995. Cultural and chemical treatments to reduce powdery scab infection on potatoes. Annual Report 987. Central Oregon Agricultural Research Center, Oregon, USA, p. 53 - 57.

16. Johnson S. 2002. Powdery Scab of Potatoes. Extension crops Specialist Bulletin \#2436. The University of Maine, Orono (MN), USA, 3p.

17. Lahert J., Kavanagh A. 1985. The fine structure of the cystosorus of Spongospora subterranea, the cause of powdery scab of potato. Canadian Journal of Botany 63: 2278-2282.

18. Merz U. 1997. Microscopical observation of the primary zoospore of Spongospora subterranea f. sp. subterranea. Plant Pathology 46: 670-674.

19. Merz. U., Falloon R. 2009. Review: powdery scab of potato - increased knowledge of pathogen biology and disease epidemiology for effective disease management. Potato Research 52: 17-37.

20. Miller J. 2001. Powdery scab. Workshop-Summary notes. Alamosa, USA. http://www.uiweb. uidaho.edu/ag/plantdisease/scabnote.htm. Consulta en enero de 2013.

21. Mohan S.K., Davis J.R., Hafez S.L. 1991. Powdery Scab of Potato. Proceedings of the University of Idaho Winter Commodity Schools 23: 242-244.
22. Montero-Astúa M., Rivera C. 2005. Biología e importancia económica de Spongospora subterranea f. sp. subterranea, agente causal de la sarna polvorienta o roña de la papa. Manejo Integrado de Plagas y Agroecología 74: 77-84.

23. Nitzan N., Cummings T., Johnson D., Miller J.S., Batchelor D.L., Olsen C., Quick R.A., Brown C.R. 2008. Resistance to root galling caused by the powdery scab pathogen Spongospora subterranea in potato. Plant Disease 92: 1643-1649.

24. Prentice M., Clayton R., Peters J., Wale S. 2007. Spongospora subterranea (Wall.) Lagerh en tubérculos de papa (Solanum tuberosum L.) utilizando papa semilla enferma con $10 \%$ de incidencia. Tesis de grado, Licenciatura en Agronomía, Instituto de Producción y Sanidad Vegetal, Universidad Austral de Chile, Valdivia-Chile, 85p.

28. Schwärzel R. 2002. Sensibilité des racines et tubercules des variétés de pommes de terre à la galepoudreuse et quelques résultats de lutte chimique. Revue Suisse Agricole 34: 261-266.

29. Tyner D., Hocart M., Lennard J., Graham D. 1997. Periderm and lenticel characterization in relation to potato cultivar, soil moisture and tuber maturity. Potato research 40: 181 - 190. 
30. Van de Graaf P., Lees A., Wale S., Duncan J. 2005. Effect of soil inoculum level and environmental factors on potato powdery scab caused by Spongospora subterranea. Plant Patholology 54: 22-28.

31. Wale S. 2000. Summary of the session on national potato production and the powdery scab situation. En: Merz, U. and A.K. Lees (eds.). The $1^{\text {st }}$ European Powdery Scab Workshop, SAC, Aberdeen, Scotland, p. 3-9.

32. Ward E., Adams M. 2010. Plasmodiopforida. En: The of life web project, http:/tolweb.org/ consulta: Marzo de 2013. 